\title{
A study on the correlation of matrix metalloproteinase MMP1 in COPD and smoking in the North Indian population
}

\author{
Vishwajeet Rohil', V K Vijayan², Raj Kumar ${ }^{3}$, Rini Joshi' ${ }^{4}$, P Pavani ${ }^{5}$, Shweta Paul ${ }^{6}$, \\ Anju Sharma ${ }^{7}$, Mujeeb ur Rahman ${ }^{8}$ \\ ${ }^{1}$ Assistant Professor, Clinical Biochemistry Unit, Department of Biochemistry, ${ }^{2} E x$-Director, Department of Pulmonary \\ Medicine, ${ }^{3}$ Director Professor, Head, Department of Respiratory Allergy \& Applied Immunology and Department of \\ Pulmonary Medicine, ${ }^{4}$ SRF, ICMR Project, Clinical Biochemistry Unit, Department of Biochemistry, ${ }^{5}$ Technical Assistant, \\ Clinical Biochemistry Unit, Department of Biochemistry, ${ }^{6}$ Junior Resident, Clinical Biochemistry Unit, Department of \\ Biochemistry, ${ }^{7}$ Ph.D. Scholar, Clinical Biochemistry Unit, Department of Biochemistry, ${ }^{8}$ Assistant Professor, Department \\ of BioStatistics, Vallabhbhai Patel Chest Institute, University of Delhi, New Delhi, India
}

A B S T R A C T

Background: Chronic Obstructive Pulmonary Disease (COPD) is characterized by airway obstruction and destruction of lung tissue, the disease for which at present there is no cure, although the treatment can slow worsening. Nearly $90 \%$ of COPD is caused by long term cigarette smoking; however, only $25 \%$ of chronic tobacco smokers develop COPD, the exact cause of this predisposition of some smokers to acquire COPD is still poorly understood at the molecular level. Lot of studies are available showing the correlation of MMP1 and asthma but not much work has been done on its correlation with COPD especially in North India. The outcome of our study was also expected to discover MMP1 as a new target for treating COPD and its progression in smokers. Aims and Objectives: The association of COPD and smoking with MMP1 gene product and SNP in the North Indian population was intended to be studied. Material and Methods: The proposed study was a case control study. In this study adults aged 30 years and above fulfilling the inclusion criteria (the criteria mentioned under the materials and methods) were considered and a total of 180 subjects were taken after determining the sample size. Pulmonary function test (PFT) was performed by Spirometry. Three main groups each consisting of 60 subjects were formed on the basis of smoking history and Spirometry: Ist group: Smokers without co-morbidity with normal PFT, Ind group: Smokers with Spirometry proved COPD and without any other co-morbidity, IIIrd group: Healthy Non-smoker controls. Quantification of metalloproteinase MMP1 in all the groups were performed in the serum with ELISA kits and Single Nucleotide Polymorphism (SNP 1G-1607 2G, ID rs1799750) studiesin the gene encoding MMP1 linked to COPD susceptibility in smokers was performed by DNA Sequencing Analysis. The correlation between the SNPs, gene product, smokingand COPD was studied. Results: MMP1 concentration was seen increased in serum of COPD and smokers when compared to healthy controls. And there is high negative correlation between ${ }^{*}$ FEV1/FVC \% (post-bronchodilator)and MMP1 in COPD compared to Smokers and Healthy Controls. However, from the results of present analysis, we could show negative correlation between MMP1 and ${ }^{*}$ FEV1/FVC \% in all the 3 groups but the correlation proves to be much more negative in Group II i.e. Smokers with COPD. Statistically Significant Positive Correlation of Pack Years with MMP1 conc., and Statistically Significant Negative Correlation between Pack Years and ${ }^{*}$ FEV1/FVC \% was seen. Conclusion: In conclusion, our present analyses did show significant association between MMP1 and COPD risk in North Indian population. MMP1 levels of COPD patients were significantly increased in smokers and may contribute to or be a marker of the pathophysiology of COPD.

Key words: COPD, MMP1, SNP, *FEV1/FVC \% (post-bronchodilator), Pack years 


\section{INTRODUCTION}

Chronic Obstructive Pulmonary Disease (COPD), debilitating airway inflammatory disease is been a foremost reason of worldwide morbidity and mortality with $75 \%$ of cases attributable to tobacco smoking Cigarette ${ }^{1}$ and in India smoking Cigarette and Bidi (tobacco wrapped in a tendu or temburni leaf). Although several fuel combustion products, exposure to biomass smoke are few threatening factors but the major risk factor for the disease is tobacco smoking. Tobacco smoking is the major risk factor for development of COPD and smoking cessation is the only currently employed intervention to slow down the disease progression. Chronic or recurrent bronchitis is a major component of COPD. It consists of bouts of increased cough and sputum production that can occur frequently. Emphysema, another component of COPD, entails the destruction of alveoli (air sacs) in the lungs, impairing their ability to bring oxygen into the body and eliminate carbon dioxide. The best known genetic risk factor for COPD is alpha-1 antitrypsin deficiency leading to Emphysema. Alpha-1 antitrypsin is a special protein that protects the lungs from enzymes known as proteases. These patients can develop lung disease even in the absence of tobacco smoking although tobacco smoking accelerates the chances of developing COPD. Endogenous protease activity is implicated in the pathophysiology of Emphysema, Chronic or recurrent bronchitis and Chronic bronchiolitis. In particular Matrix Metalloproteinases (MMP's), a large family of structurally related metalloendopeptidases that degrade components of extracellular matrix are crucial to maintain homeostasis.

Despite the clinical importance of COPD, relatively few studies have searched for genetic factors using modern molecular genetic techniques. COPD is a complex disease that is still poorly understood at the molecular level. A complex interplay between genetic and environmental factors is likely, and many distinct genes or groups of genes will be involved. In multifactorial diseases such as COPD, disease expression is influenced by interactions between multiple genes, and modulated by interacting non-genetic factors such as the environment or infection. It is suggested that multiple genetic factors and genotype-by-environment interactions are involved in the development of complex-trait diseases such as COPD. ${ }^{2}$ Although COPD is the fifth leading cause of worldwide morbidity and mortality a lot of questions about the its pathogenesis and associated molecular mechanisms are still unanswered. The aim of the present study was to elucidate the correlation of Matrix Metalloproteinase MMP1 in COPD and Smoking in the North Indian Population. In addition an attempt was made to assess SNP in MMP1 gene (rs1799750, 1G-1607 2G) (Table 1). The predisposition of some smokers to acquire COPD has been investigated by studying the polymorphism in metalloproteinases gene,
MMP1 and its association with smoking and COPD were investigated in an effort to elucidate the mechanism of development of COPD in smokers.

This is an epidemiologic, population based study conducted at Viswanathan Chest Hospital,Vallabhbhai Patel Chest Institute (VPCI). The subjects included in the study were representatives comprising urban and rural populations of North India.

The outcome of the proposed project is also expected to discover some new targets (e.g. any specific metalloproteinase) for treating COPD and its progression in smokers.

The matrix metalloproteinase (MMP) family of enzymes consists of 25 zinc-dependent endopeptidases in mice and 24 in humans. Many members of the MMP family are upregulated in the lungs of humans with inflammatory diseases. To understand the biology of MMPs in a variety of relevant human pathological conditions such as allergic inflammation, tissue injury and repair, remodeling, and host defense against pathogens. ${ }^{3,45}$ At least eight of the known human MMP genes (MMP-1, -3, -7, -8, -10, -12, -13 and -20 ) are clustered on chromosome 11 at 11q21-23. Other MMP genes are scattered among chromosomes 1, $8,12,14,16,20$, and 22. MMPs are formed as zymogens and activated following secretion either by cleavages in the hydrophobic propeptide domain that is located in the $\mathrm{NH} 2$ terminus or in the trans- Golgi network by furin-like protein convertases. As in all tissues, expression of MMPs in the lung is a highly regulated process, and understanding its regulation could, in part, shed light into their biological function in normal developmental processes, such as lung branching morphogenesis, and in many pathological conditions, such as asthma or chronic obstructive lung disease. ${ }^{6-10}$ Some of the known targets of MMPs in the lung include extracellular matrix (ECM) molecules, growth factors, chemokines, proteinases, and cell surface proteins, such as adhesion molecules. The functional significance of the interactions between MMPs and their substrates in bronchoalveolar fluid and in the lung parenchyma is a novel concept that is currently being explored, but because of the intricacy of these enzymes and their substrates, much of this type of information remains poorly understood. However, a dedicated effort is now underway to identify the many as yet undiscovered proteins that are undoubtedly critical substrates of the MMPs. ${ }^{11}$ Many members of the MMP family are upregulated in the lungs of humans with inflammatory diseases. MMPs are critical for lung development and tissue repair processes and over the past decade a large effort has been devoted in determining their role in various inflammatory diseases of the lung. The use of genetic approaches has increased the understanding of the contribution of MMPs in animal models of disease; however, much less is known about how MMPs may behave 
in the pathogenesis of human lung disease. Due to the complexity of human lung inflammatory conditions, the fact that most human studies are performed on lung diseases in different stages of their progression, and the heterogeneous nature of the human population, a clear role for the MMPs in the pathogenesis of lung diseases is difficult to conclude. Nonetheless, the resurgence of MMPs in the lung during inflammation has made their manipulation an appealing therapeutic strategy. Although polymorphisms in a large number of genes have been determined, the polymorphisms of MMP genes that encode for central enzymes involved in the progression of COPD have not been analyzed extensively in association with this disease. A role for the MMPs has been suggested in the pathogenesis of pulmonary emphysema. ${ }^{12}$ Alveolar macrophages can produce several MMPs including MMP-12 (macrophage elastase), MMP-1, MMP-9, smaller amounts of MMP-3, and MMP-7. Unlike neutrophils and monocytes, which store proteases potentially for rapid release, macrophages monitor and respond to their environment. Dysregulated expression of MMPs either directly or indirectly by cigarette smoke exposure could lead to the lung destruction characteristic of emphysema. Macrophages can also produce elastolytic cysteine proteases including cathepsins $\mathrm{K}$, L, and S. If these proteinases are secreted in an acidic environment, they can cause significant lung destruction. ${ }^{13}$ The balance between proteases and antiproteases is thought to play a key role in cigarette smoke-induced chronic lung disease. An increase in collagen deposition in the bronchial wall is observed in chronic bronchitis, whereas histopathologic evidence of extracellularmatrix (ECM) degradation is one of the hallmarks of emphysema, which can be induced in rodents by the intratracheal instillationof elastases. Moreover, deficiency of 1-antiproteinaseis a known genetic cause of emphysema. The two main elastase-producing cell types in the airways of smokers are neutrophils and macrophages, but macrophages are by far the most abundant cell type in bronchoalveolar spaces, particularly in cigarette smokers. ${ }^{14}$ Macrophages also produce tissue inhibitors of metalloproteinases (TIMPs), which bind to the active forms of MMPs. ${ }^{15}$ Several studies suggest that the balance between regulated macrophage MMP and TIMP may be an important determinantof the clinical expression of chronic obstructive pulmonary disease (COPD). ${ }^{16,17}$

\section{MATERIALS AND METHODS}

A total of 180 members (Figure 1) aging 30 years and above were classified into 3 groups based on clinical and functional diagnosis of COPD associated with smoking (Figure 1). Considering the prevalence rate of COPD in India which is $4.1 \%$ and $5 \%$ sampling error, the minimum sample size of $\mathrm{n}=60$ was determined for the study. The quantity, duration and degree of exposure to tobacco smoked was determined through clinical interview followed by filling of questionnaire accessible in bilingual languages-Hindi and English. The inclusion criterion included healthy adults aged 30 years and above for control, history of exposure to tobacco smoking either 5 cigarettes or bidis a day for 5 years for healthy smokers and Spirometry proved FEV1 \% cases of COPD with FVC ratio $<70 \%$ falling in stages I to III of COPD.

Three main groups of 60 subjects each were formed on the basis of smoking history and Spirometry.

I. The first group comprising Smokers without comorbidity with normal PFT

II. Second group consisting of Smokers with Spirometry proved COPD and without any other co-morbidity

III. Third group involving Healthy Non-smoker controls.

COPD phenotype- Only Spirometry proved cases with FEV1/FVC ratio $<70 \%$ will be labeled as COPD phenotypes i.e. stage $\mathrm{I}$ and above based on the GOLD guidelines ${ }^{18}[\mathrm{FEV} 1$ value refer to post-bronchodilator FEV1].

Controls - Normal PFT i.e. with an FEV1/FVC ratio $\geq 70 \%$ and predicted FEV1 $\geq 80 \%$ without chronic symptoms (cough and/or sputum production).

Smokers- Subject smoking $>5$ cigarettes or bidis a day for $>$ five years. Pack years will also be calculated for each smoker and noted for analyses.

Non-smokers- Subject who have not smoked cigarettes and/ or bidis or consumed related products containing nicotine at all.

However, among "smokers," a history of cigarette smoking can range from patients who smoked a few cigarettes a day

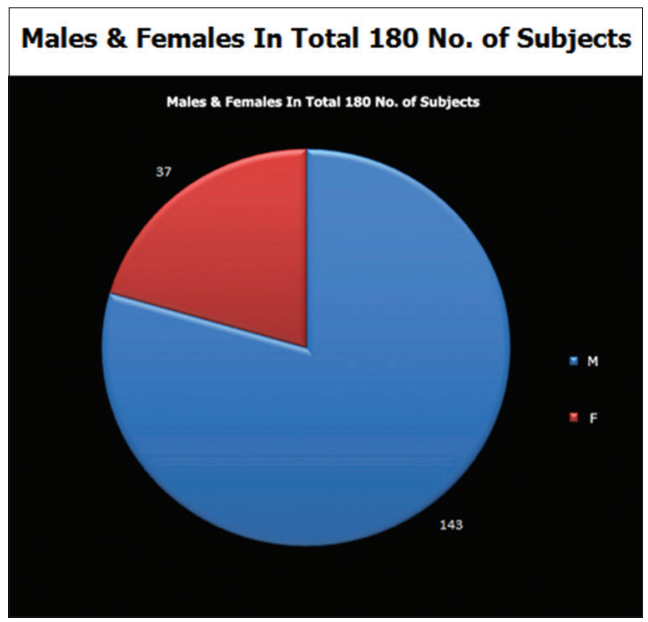

Figure 1: The Experiment was conducted in total 180 subjects of which there were 143 Males and 37 Females. 


\section{Table 1: Primers for MMP 1}

\begin{tabular}{|c|c|c|c|}
\hline SNP ID & SNP & Primer sequence $5^{\prime} \rightarrow 3^{\prime}$ & Standardized PCR program \\
\hline \multirow[t]{3}{*}{ rs1799750 } & 1G-16072G & $\begin{array}{l}\text { Forward } \\
\text { 5'-TCGTGAGAATGTCTTCCCATT-3' }\end{array}$ & $\begin{array}{l}95^{\circ} \mathrm{C} \text { for } 10 \mathrm{~min} \text {, followed by } 30 \text { cycles of }\left(95^{\circ} \mathrm{C} \text { for } 30 \mathrm{~s} \text {, }\right. \\
\left.58^{\circ} \mathrm{C} \text { for } 30 \mathrm{~s}, 72^{\circ} \mathrm{C} \text { for } 30 \mathrm{~s}\right) \text {, and a final extension at } 72^{\circ} \mathrm{C} \\
\text { for } 5 \mathrm{~min} .\end{array}$ \\
\hline & & Reverse & \\
\hline & & 5'-TCTTGGATTGATTTGAGATAAGTGAAATC-3' & \\
\hline
\end{tabular}

for a few years to patients who smoked packs of cigarettes daily for decades. Pack years was also calculated for each smoker and noted for analyses.

The pack-year is a unit for measuring the amount a person has smoked over a long period of time. It is calculated by multiplying the number of packs of cigarettes smoked per day by the number of years the person has smoked.

Number of pack-years $=($ packs smoked per day $) \times($ years as a smoker)

or

Number of pack-years $=$ (number of cigarettes smoked per day $\times$ number of years smoked)/20 (1 pack has 20 cigarettes).

A pack-year is smoking 20 cigarettes a day for one year. Quantification of pack-years smoked is important in clinical care, where degree of tobacco exposure is correlated to risk of disease

COPD diagnosis was confirmed by medical history and Pulmonary function tests (PFT) by spirometry results were interpreted according to the GOLD guidelines. The subjects who had major illness systemic disorder, any other cause of airflow limitation, Personal history or family history of cancer, leukoplakia, skin allergy, food allergy, asthma, pulmonary tuberculosis, diabetes mellitus or any kind of exposure to drugs apart from tobacco except occasional, social drinking were excluded from the study. Patients with COPD who participated in this study were clinically stable and are exclusive of COPD stage IV or 0.

The criterion for inclusion is was following:

- Healthy adults, aged 30 years and above, non-smokers and non-tobacco consumers will be taken as control in the proposed study.

- For smoking groups in the study the adults aged 30 years and above, smoking more than 5 cigarettes or bidis a day for more than five years will be included.

- Persons willing to participate in the study and come regularly when required for the study.

- The following examination of the subjects was done before inclusion:
General physical examination was done that includes level of consciousness, pallor, cyanosis, pedal edema, blood pressure, examination of cardio respiratory system. X-ray chest was done and Spirometry had been performed in all the subjects. Chest radiographs and histories were evaluated in all the subjects to exclude other causes of airflow limitation such as pulmonary tuberculosis, bronchial asthma and heart failure. Other clinical laboratory investigations were done wherever seemed appropriate to rule out specific diseases.

The person with normal results in all the above examinations and also Spirometry proved cases of $\mathrm{COPD}^{18}$ with FEV1/FVC ratio $<70 \%$ as described previously without any other illness were included in our study.

Persons were not included in our study if they had any of the following:

- Personal history or family history of cancer, leukoplakia, skin allergy, food allergy, asthma, pulmonary tuberculosis, diabetes mellitus.

- Any major illness.

- Any other cause of airflow limitation.

- Addiction to any kind of drugs apart from tobacco except occasional, social drinking. Though alcohol consumption is very common with smoking but we had excluded regular heavy drinkers from our studies. And in social drinking too we suggested the persons not to drink and if person takes it even then, the date and quantity of alcohol intake had been mentioned in the study.

Informed consent was obtained from each subject and the protocol was approved by Ethical committee, VPCI.

All subjects were evaluated through spirometry by postbronchodilator FEV1/FVC so as to avoid the overdiagnosis of airflow obstruction with Pre bronchodilator criteria as prescribed in Gold guidelines on Spirometric Classification of Severity and Stages of COPD.

Diagnosis of COPD was thereby confirmed by the history of tobacco smoking accompanied with pulmonary function tests through spirometry.

The patients were enrolled from the Out Patient Department of Viswanathan Chest Hospital, Vallabhbhai 
Patel Chest Institute. The patients were selected on the basis of the selection criteria as mentioned above after taking written consent from them.

A study ${ }^{19}$ in a random population sample found that the post-bronchodilator FEV1/FVC exceeded 0.70 in all age groups, supporting the use of this fixed ratio. ${ }^{20}$ Pre bronchodilator criteria for detection of airflow obstruction overestimate the diagnosis of airflow obstruction and by using post bronchodilator criteria for airway obstruction on spirometry, decreases this over diagnosis of the condition. $^{21,22}$ Therefore we have correlated with post bronchodilator FEV1/FVC. ${ }^{19-23}$

Venous blood samples were collected from the study subjects in two separate $3 \mathrm{ml}$ red and lavender vacutainers, red the one without anticoagulant for separation of serum and the lavender one which contains EDTA for whole blood collection. The serum was collected from red vacutainer after allowing to clot the blood at room temperature for 30 minutes and then centrifuging at $1000 \mathrm{~g}$ for $15 \mathrm{~min}$. The collected serum was stored at $-20^{\circ} \mathrm{C}$ for quantification of MMP1 gene. Genomic DNA was extracted from whole blood collected in EDTA Vacutainer using commercially available DNA Extraction Kit from MDI, Advanced Microdevices Pvt. Ltd., according to the manufacturer's protocol. The extracted genomic DNA purity was checked by Nanodrop 2000, ThermoScientific. The A260/A280 ratio of 1.8 and above was obtained in the samples elucidating the good quality of DNA.

\section{MIMP1 gene (Table 1)}

PCR Conditions: Polymerase chain reaction (PCR) was carried out on gDNA using specific forward and reverse primer pairs designed to span the MMP 1.PCR conditions were performed on gradient PCR thermal cycler from Bio-Rad (India) Pvt. Ltd. in 96 well plate. Each $25 \mu \mathrm{l}$ volume contained $25 \mathrm{ng}$ of gDNA, $0.2 \mathrm{mM}$ dNTPs (MP Biomedicals), 1 X Taq polymerase buffer (MP Biomedicals), $0.1 \mu \mathrm{M}$ primers (Sigma, Aldrich) and 1 Unit of Taq polymerase enzyme (MP Biomedicals) per reaction. DNA was initially denatured at $95^{\circ} \mathrm{C}$ for $10 \mathrm{~min}$ followed by 30 cycles of $\left(95^{\circ} \mathrm{C}\right.$ for 30 seconds, $58^{\circ} \mathrm{C}$ for $30 \mathrm{sec}$ and $72^{\circ} \mathrm{C}$ for $30 \mathrm{sec}$ ) and a final extension step of $72^{\circ} \mathrm{C}$ for $5 \mathrm{~min}$.

The PCR product i.e., amplicons from the previous step were treated with exonuclease I (Fermentus Pvt. Ltd.) to remove the unused primers and shrimp alkaline phosphatase (SAP) (Fermentus Pvt. Ltd.) to remove the 3' OH group from unused dNTPs. DNA Sequencing of cleaned up PCR products from the previous step were performed on an automated DNA sequencer from Applied Biosystems. SNP in MMP1 which was previously described to be associated with COPD, asthma, airway hyper-responsiveness, or excessive decline in FEV1, is being genotyped by following Sanger principle, using an automated DNA sequencer as per the manufacturer's instructions.

Quantification of MMP1: Concentration of MMP1 was determined in the serum by commercially available ELISA kits (Boster Biological Technology., Ltd; and Cusabio Biotech Co., Ltd) according to the manufacturer's instructions.

\section{Statistical analysis}

The data was presented in Median (Interquartile range) (Table 2). The comparison of parameters in-between groups was tested by Kruskal-Wallis test followed by Mann-Whitney $U$ test (Tables 4-8). Correlation Coefficient among the parameters in all 180 subjects of all the three groups was calculated by both Spearman's Rank Correlation and Pearson methods (Tables 9-15). All analyses were performed in SPSS (version 12.0.1 for windows, SPSS Inc., IL, USA). P $<0.05$ was considered to be highly significant.

\section{RESULTS}

The concentration of MMP1 was calculated in $\mathrm{pg} / \mathrm{ml}$ from standard curve (Figure 2 and Table 3 ) after taking mean of the 2 replicates at $450 \mathrm{~nm}$.

Amplification of gene MMP1 in the above mentioned PCR conditions was performed successfully and the resultant

$\begin{aligned} & \text { Table 2: The Data presented in median } \\
& \text { (Interquartile range) }\end{aligned}$
\begin{tabular}{llc}
\hline S. No. & Parameters & $\begin{array}{c}\text { Median (Interquartile range) } \\
\text { (Sample size, N=180) }\end{array}$ \\
\hline 1 & Age & $52.50(25)$ \\
2 & ${ }^{*} \mathrm{FEV} 1 / \mathrm{FVC} \%$ & $80.00(32.75)$ \\
3 & MMP1 pg/ml & $788.27(714.55)$ \\
\hline
\end{tabular}

\begin{tabular}{lccc}
\multicolumn{4}{l}{ Table 3: MMP1 } \\
$\begin{array}{l}\text { MMP 1 } \\
\text { conc. pg/ml }\end{array}$ & Replicate 1 & Replicate 2 & $\begin{array}{c}\text { Mean OD } \\
\text { at 450 } \mathbf{~ n m}\end{array}$ \\
\hline 156 & 0.027 & 0.031 & 0.029 \\
313 & 0.030 & 0.036 & 0.033 \\
625 & 0.072 & 0.066 & 0.069 \\
1250 & 0.135 & 0.127 & 0.131 \\
2500 & 0.292 & 0.293 & 0.291 \\
5000 & 0.505 & 0.555 & 0.53 \\
10000 & 1.158 & 1.148 & 1.153 \\
\hline
\end{tabular}


amplicons obtained were then subjected to DNA sequencing. None of the SNPs under the study were detected in MMP1 gene (rs1799750, 1G-1607 2G) in any of the three groups.

Kruskal-Wallis test

\begin{tabular}{lccc}
\multicolumn{4}{l}{ Table 4: Test statistics } \\
\hline Parameters & Chi-square & Degrees of freedom & P value \\
\hline Age & 66.23 & 2 & 0.0001 \\
${ }^{*} \mathrm{FEV} 1 / \mathrm{FVC} \%$ & 132.056 & 2 & 0.0001 \\
$\mathrm{MMP1}$ & 66.48 & 2 & 0.0001 \\
\hline *FEV1/FVC \% post-bronchodilator $^{\mathrm{F}}$ & &
\end{tabular}

Table 5: Correlation among the parameters in all 180 subjects of all the three groups (except pack years, which was correlated in group I and II) were calculated by Spearman's rank correlation

\begin{tabular}{lcccc}
\hline $\begin{array}{l}\text { Spearman's } \\
\text { rho }\end{array}$ & FEV1/FVC\% & $\begin{array}{c}\text { MMP1 } \\
\text { Conc. }\end{array}$ & $\begin{array}{c}\text { Age } \\
\text { years }\end{array}$ & $\begin{array}{c}\text { Pack } \\
\text { years }\end{array}$ \\
\hline Pack (Years) & $-0.608^{* *}$ & $0.419^{* *}$ & $0.552^{* *}$ & 1.000 \\
$\quad \begin{array}{l}\text { Correlation } \\
\text { Coefficient }\end{array}$ & 0.000 & 0.000 & 0.000 & $\cdot$ \\
$\quad \begin{array}{l}\text { Sig. (2-tailed) } \\
\text { N }\end{array}$ & 120 & 120 & 120 & 120 \\
\hline ** Correlation is significant at the 0.01 level (2-tailed). & & \\
\hline
\end{tabular}

**. Correlation is significant at the 0.01 level (2-tailed).

Mann-Whitney Test (Tables 6-8)

Table 6: Median (inter quartile) between Ist $_{\text {group }}$ (smokers without co-morbidity with normal PFT) and IInd group (smokers with spirometry proved COPD and without any other co-morbidity)

\begin{tabular}{lccc}
\hline Parameters & Group I & Group II & P value \\
\hline Age & $52.00(22.75)$ & $63.00(15.75)$ & 0.0001 \\
*FEV1/FVC \% $^{\text {M }}$ & $80.50(9.50)$ & $43.00(17.00)$ & 0.0001 \\
MMP1 & $823.34(528.24)$ & $1099.50(988.50)$ & 0.001 \\
Pack years & $7.75(14.72)$ & $32.12(43.37)$ & 0.0001 \\
\hline *FEV1/FVC \% post-bronchodilator & &
\end{tabular}

Table 7: Between Ist group (smokers without co-morbidity with normal PFT) and IIIrd group (healthy non-smoker controls)

\begin{tabular}{lccc}
\hline Parameters & Group I & Group III & P value \\
\hline Age & $52.00(22.75)$ & $36.50(13.75)$ & 0.0001 \\
${ }^{*}$ FEV1/FVC \% & $80.50(9.50)$ & $87.00(5.5)$ & 0.0001 \\
MMP1 & $823.34(528.24)$ & $428.80(195.07)$ & 0.0001 \\
\hline
\end{tabular}

*FEV1/FVC \% post-bronchodilator

\begin{tabular}{|c|c|c|c|}
\hline Parameters & Group II & Group III & $P$ value \\
\hline Age & $63.00(15.75)$ & $36.50(13.75)$ & 0.0001 \\
\hline${ }^{*}$ FEV1/FVC \% & $43.00(17.00)$ & $87.00(5.5)$ & 0.0001 \\
\hline MMP1 & 1099.50 (988.50) & $428.80(195.07)$ & 0.0001 \\
\hline
\end{tabular}

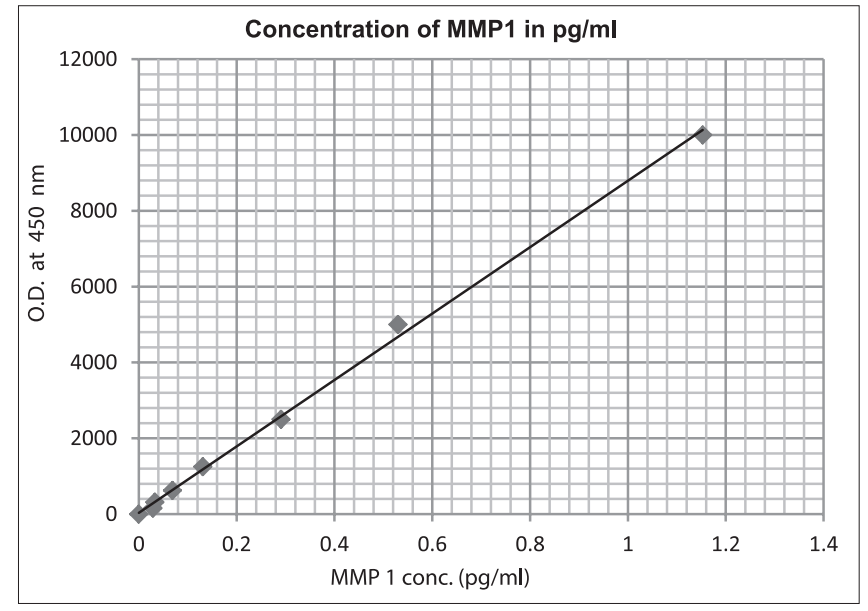

Figure 2: MMP1 standard curve

DNA Sequencing Analysis: The SNP under study was not detected in MMP1 gene (rs1799750,1G-1607 2G) in any sample in any of the three groups.

\section{DISCUSSION}

Matrix metalloproteinase is a family of zinc-dependent endopeptidases degrading all the main protein components of the extracellular matrix and playing an essential role in tissue remodeling and repair associated with development and inflammation. MMP-1 is located in close proximity on chromosome 11. Many clinical studies suggested that MMPs were involved in COPD as concentration of MMPs in serum or induced sputum in patients was higher than that in non-COPD patients or healthy volunteers. MMPs play an important role in the turnover of almost all extracellular matrix molecules and are therefore involved in COPD pathogenesis. The degree of COPD severity is dependent on lung function. As of 2013 COPD affects 329 million people or nearly 5 percent of the global population. ${ }^{24,25}$ It typically occurs in people over the age of 40. Males and females are affected equally commonly. In 2013 it resulted in 2.9 million deaths, up from 2.4 million deaths in $1990 .{ }^{26}$ More than $90 \%$ of these deaths occur in the developing world. The number of deaths is projected to increase further because of higher smoking rates in the developing world, and an aging population in many countries. ${ }^{27}$ It resulted in an estimated economic cost of $\$ 2.1$ trillion in $2010 .{ }^{28}$ The main findings of this work is that metalloproteinase 1(MMP1) concentration increased in serum of COPD and smokers when compared to healthy controls (Tables 7 and 8 ). There is high negative correlation between FEV1/ FVC\% and MMP1 in COPD compared to smokers and healthy controls (Table 9). In summary, the present study demonstrates increased concentrations of MMP1 activity in COPD patients compared with cigarette smokers or control subjects. In conclusion the MMP1 levels of COPD patients

Asian Journal of Medical Sciences | Jan-Feb 2017 | Vol 8 | Issue 1 
differs markedly from that of smokers and controls and may contribute to or be a marker of the different pathophysiologies of COPD.

However, from the results of present analysis, we could show negative correlation between MMP 1 and $* \mathrm{FEV} / \mathrm{FVC} \%$ in all the 3 groups but the correlation proves to be much more negative in Group II i.e. Smokers with COPD as evidenced by the values depicted in Clustered Bar column graph and also by the trendline in the Correlation graph. A Steep trendline in Group II Graph (Figure 4) where almost many of the points are clustered resembling a straight line with a negative slope clearly elucidates a high negative correlation compared to the other 2 correlation graphs of Group I and Group III (Figures 3 and 5) which show low negative correlation as the points tend to fall, but are not clustered in

\begin{tabular}{|c|c|c|c|c|}
\hline Spearman's rho & FEV1/FVC \% & MMP1 Conc. & Age years & Pack years \\
\hline \multicolumn{5}{|l|}{ 1.*FEV1/FVC \% } \\
\hline Correlation coefficient & 1.000 & $-0.845^{\star *}$ & $-0.558^{* *}$ & $-0.608^{* *}$ \\
\hline Sig. (2-tailed) & & 0.000 & 0.000 & 0.000 \\
\hline $\mathrm{N}$ & 180 & 180 & 180 & 120 \\
\hline Sig. (2-tailed) & 0.000 & 0.000 & 0.000 & 0.000 \\
\hline $\mathrm{N}$ & 180 & 180 & 180 & 120 \\
\hline \multicolumn{5}{|l|}{ 2. MMP1 } \\
\hline Correlation coefficient & $-0.845^{\star *}$ & 1.000 & $0.426^{\star \star}$ & $0.419^{* *}$ \\
\hline Sig. (2-tailed) & 0.000 & & 0.000 & 0.000 \\
\hline $\mathrm{N}$ & 180 & 180 & 180 & 120 \\
\hline Sig. (2-tailed) & 0.000 & 0.000 & 0.000 & 0.000 \\
\hline $\mathrm{N}$ & 180 & 180 & 180 & 120 \\
\hline \multicolumn{5}{|l|}{ 3. Age (Years) } \\
\hline Correlation coefficient & $-0.558^{* *}$ & $0.426^{* *}$ & 1.000 & $0.552^{* *}$ \\
\hline Sig. (2-tailed) & 0.000 & 0.000 & . & 0.000 \\
\hline $\mathrm{N}$ & 180 & 180 & 180 & 120 \\
\hline \multicolumn{5}{|l|}{ 4. Pack (Years) } \\
\hline Correlation coefficient & $-0.608^{* *}$ & $0.419^{* *}$ & $0.552^{\star *}$ & 1.000 \\
\hline Sig. (2-tailed) & 0.000 & 0.000 & 0.000 & . \\
\hline $\mathrm{N}$ & 120 & 120 & 120 & 120 \\
\hline
\end{tabular}

\section{Table 10: Group I: Correlations by Spearman's rank correlation method}

\begin{tabular}{|c|c|c|c|c|}
\hline Parameter & Spearman's rho & FEV1/FVC\% & Pack years & MMP1 \\
\hline \multirow[t]{3}{*}{ FEV1/FVC\% } & Correlation coefficient & 1.000 & $-0.426^{* *}$ & $-0.870^{* *}$ \\
\hline & Sig. (2-tailed) & 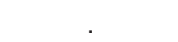 & 0.001 & 0.000 \\
\hline & $\mathrm{N}$ & 60 & 60 & 60 \\
\hline \multirow[t]{3}{*}{ Pack years } & Correlation coefficient & $-0.426^{\star *}$ & 1.000 & $0.332^{* *}$ \\
\hline & Sig. (2-tailed) & 0.001 & . & 0.010 \\
\hline & $\mathrm{N}$ & 60 & 60 & 60 \\
\hline \multirow[t]{3}{*}{ MMP1 } & Correlation coefficient & $-0.870^{* *}$ & $0.332^{* *}$ & 1.000 \\
\hline & Sig. (2-tailed) & 0.000 & 0.010 & . \\
\hline & $\mathrm{N}$ & 60 & 60 & 60 \\
\hline
\end{tabular}

\section{Table 11: Group I: Correlations by Pearson correlation method}

\begin{tabular}{llccc}
\hline Parameter & Pearson correlation & FEV1/FVC $\%$ & Pack years & MMP1 \\
\hline FEV1/FVC\% & Pearson correlation & 1.000 & $-0.353^{* *}$ & $0.588^{* *}$ \\
& Sig. (2-tailed) & & 0.006 & 0.000 \\
Pack years & Pearson correlation & 60.000 & 60 & 60 \\
& Sig. (2-tailed) & $-0.353^{* *}$ & 1.000 & $0.284^{*}$ \\
MMP1 & N & 0.006 & 60.000 & 0.028 \\
& Pearson correlation & 60 & $0.284^{*}$ & 60 \\
& Sig. (2-tailed) & $-0.588^{* *}$ & 0.028 & 1.000 \\
& $N$ & 0.000 & 60 & 60.000 \\
\hline
\end{tabular}

**. Correlation is significant at the 0.01 level (2-tailed). *. Correlation is significant at the 0.05 level (2-tailed). 
Table 12: Group II: Correlations by Spearman's rank correlation method

\begin{tabular}{|c|c|c|c|c|}
\hline Parameter & Spearman's rho & FEV1/FVC\% & Pack years & MMP1 \\
\hline \multirow[t]{3}{*}{ FEV1/FVC\% } & Correlation coefficient & 1.000 & $-0.383^{* *}$ & $-0.985^{\star \star}$ \\
\hline & Sig. (2-tailed) & & 0.003 & 0.000 \\
\hline & $\mathrm{N}$ & 60 & 60 & 60 \\
\hline \multirow[t]{3}{*}{ PACK YRS } & Correlation coefficient & $-0.383^{* *}$ & 1.000 & $0.390^{* *}$ \\
\hline & Sig. (2-tailed) & 0.003 & . & 0.002 \\
\hline & $\mathrm{N}$ & 60 & 60 & 60 \\
\hline \multirow[t]{3}{*}{ MMP1 } & Correlation coefficient & $-0.985^{\star \star}$ & $0.390^{\star *}$ & 1.000 \\
\hline & Sig. (2-tailed) & 0.000 & 0.002 & . \\
\hline & $\mathrm{N}$ & 60 & 60 & 60 \\
\hline
\end{tabular}

\begin{tabular}{|c|c|c|c|}
\hline Parameter & FEV1/FVC\% & $\begin{array}{l}\text { Pack } \\
\text { years }\end{array}$ & MMP1 \\
\hline \multicolumn{4}{|l|}{ FEV1/FVC\% } \\
\hline $\begin{array}{l}\text { Pearson } \\
\text { Correlation }\end{array}$ & 1.000 & $-0.395^{* *}$ & $-0.769^{\text {** }}$ \\
\hline Sig. (2-tailed) & - & 0.002 & 0.000 \\
\hline $\mathrm{N}$ & 60.000 & 60 & 60 \\
\hline \multicolumn{4}{|l|}{ PACK YRS } \\
\hline $\begin{array}{l}\text { Pearson } \\
\text { Correlation }\end{array}$ & $-0.395^{\star *}$ & 1.000 & $0.406^{\star \star}$ \\
\hline Sig. (2-tailed) & 0.002 & - & 0.001 \\
\hline $\mathrm{N}$ & 60 & 60.000 & 60 \\
\hline \multicolumn{4}{|l|}{ MMP1 } \\
\hline $\begin{array}{l}\text { Pearson } \\
\text { Correlation }\end{array}$ & $-0.769^{* *}$ & $0.406^{* *}$ & 1.000 \\
\hline Sig. (2-tailed) & 0.000 & 0.001 & - \\
\hline $\mathrm{N}$ & 60 & 60 & 60.000 \\
\hline
\end{tabular}

Table 14: Group III: Correlations by Spearman's Rank Correlation method

\begin{tabular}{llcc}
\hline Parameter & Spearman's rho & FEV1/FVC & MMP1 \\
\hline FEV1/FVC & Correlation & 1.000 & $-0.987^{* *}$ \\
& Coefficient & & \\
& Sig. (2-tailed) & - & 0.000 \\
\multirow{4}{*}{ MMP1 } & Correlation & $-0.987^{* *}$ & 60 \\
& Coefficient & & 1.000 \\
& Sig. (2-tailed) & 0.000 & - \\
& $\mathrm{N}$ & - & - \\
& & 60 & 60 \\
\hline
\end{tabular}

**. Correlation is significant at the 0.01 level (2-tailed). *. Correlation is significant at the 0.05 level (2-tailed).

a straight line. The studies contained a limited sample size but the results obtained were stable enough. The factors such as smoking and lung function tests were elucidated to be confounders in present analysis

In addition, the decline in the FEV1/FVC ratio was accelerated in I and II Groups who are smokers, overall smokers with or without COPD have lower than normal lung function when compared to non smokers as evidenced in our study.

\begin{tabular}{lcc}
$\begin{array}{l}\text { Table 15: Group III: Correlations by Pearson } \\
\text { Correlation method }\end{array}$ \\
\hline Parameter & FEV1/FVC & MMP1 \\
\hline FEV1/FVC & 1.000 & $-0.729^{* *}$ \\
Pearson Correlation & - & 0.000 \\
Sig. (2-tailed) & 60.000 & 60 \\
N & & \\
MMP1 & $-0.729^{* *}$ & 1.000 \\
Pearson Correlation & 0.000 & - \\
Sig. (2-tailed) & 60 & 60.000 \\
N &
\end{tabular}

**. Correlation is significant at the 0.01 level (2-tailed) *. Correlation is significant at the 0.05 level (2-tailed)

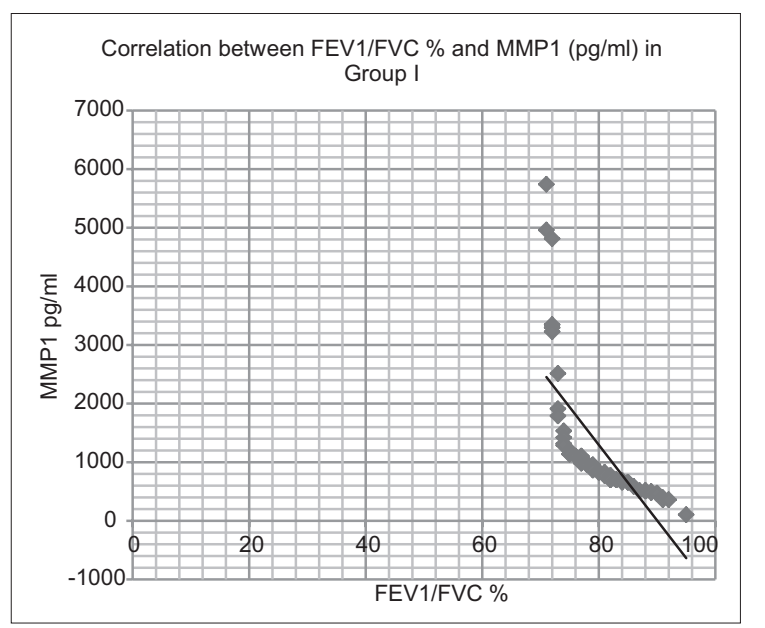

Figure 3: Group I: Correlations

Tables 10 and 11 of Group I shows statistically significant positive correlation of pack years with MMP1 conc., it was found to be significant at 0.05 level ( 2 tailed by Pearson correlation). There was statistically significant negative correlation between pack years and FEV1/FVC \% (Significant at 0.01 level, 2 tailed by Spearman \& Pearson correlation).

Tables 12 and 13 of Group II shows statistically significant positive correlation of pack years with MMP1 conc. (Significant at 0.01 level, 2 tailed by Spearman \& Pearson correlation). There was statistically significant negative 


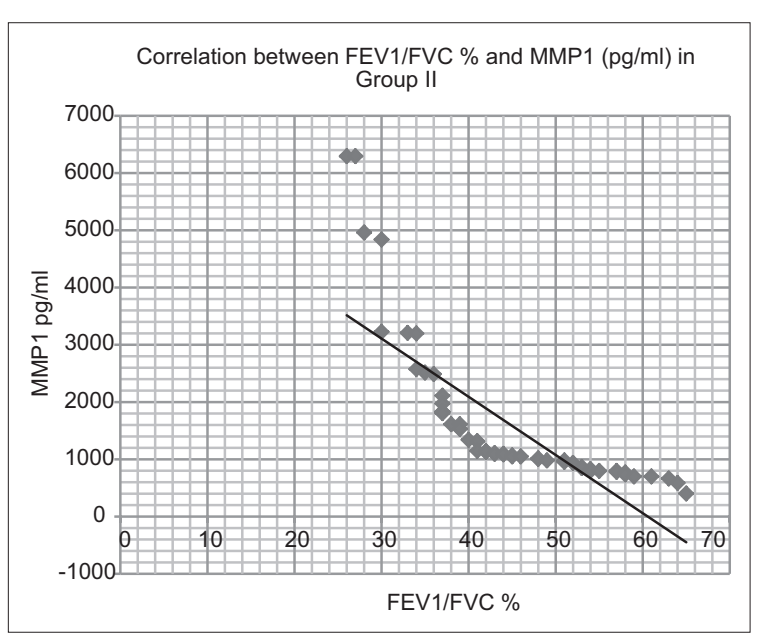

Figure 4: Group II: Correlations

correlation between pack years and FEV1/FVC \% (Significant at 0.01 level, 2 tailed by Spearman \& Pearson correlation)

There were some limitations in the present analysis. First, the sample size was too small. The quantity of patients in these studies was just 180 . However, it was estimated that there were about 200 million COPD patients in the world. In other words, only a small part of patients were recruited to study. Second, the data we obtained was not comprehensive. The studies were exclusively on North Indian Population. Moreover, the occurrence of COPD is not dependent on one gene but a cluster of genes, so the gene linkage is important for exploring disease pathogenesis. Thus in conclusion, our present analyses did show significant association between MMP1 and COPD risk in North Indian population and MMP1 may contribute to or be a marker of the pathophysiology of COPD.

However, we found that tobacco smoking was a risk factor in the subpopulation relatively worsening lung function. So, it may be helpful to screen out potential severe COPD patients by detecting MMP1. In light of cited deficiencies in the conducted study, there is a great need of more such studies including large population using various other suspected SNPs and paying much attention to gene linkage in order to confirm the role of MMP1 SNPs in smokers and COPD susceptibility. These data thus emphasize the need for further research regarding gene function in COPD that will ultimately contribute to future target oriented therapies, gene therapies for this significant disease in the North Indian population, the disease for which at present there is no cure although the treatment can slow worsening. Based upon our results, we can conclude the MMP1 be a potential a marker for the pathophysiology of COPD and also can be used as a target in development of future therapeutic strategies to treat COPD.

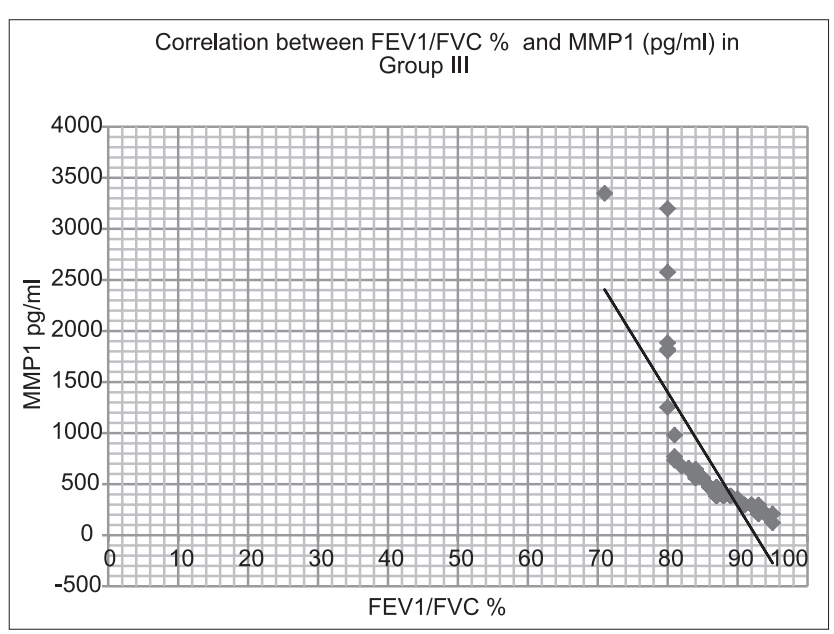

Figure 5: Group III: Correlations

\section{ACKNOWLEDGEMENTS}

The financial assistance by INDIAN COUNCIL OF MEDICAL RESEARCH is gratefully acknowledged.

\section{REFERENCES}

1. Lokke $A$, Lange $P$, Scharling $H$, Fabricius $P$ and Vestbo J. Developing COPD: a 25 year follow up study of the general population. Thorax 2006; 61(11):935-939.

2. Lander ES and Schork NJ. Genetic dissection of complex traits. Science 1994; 265:2037-2048.

3. Atkinson JJ and Senior RM. Matrix metalloproteinase-9 in lung remodeling. Am J Respir Cell Mol Biol 2003; 28: 12-24.

4. Coussens LM, Shapiro SD, Soloway PD and Werb Z. Models for gain-of-function and loss-of-function of MMPs. Transgenic and gene targeted mice. Methods Mol Biol 2001; 151: 149179.

5. Lagente V, Manoury B, Nenan S, Le Quement C, MartinChouly $C$ and Boichot $E$. Role of matrix metalloproteinases in thedevelopment of airway inflammation and remodeling. Braz J Med Biol Res 2005; 38: 1521-1530.

6. Demedts IK, Brusselle GG, Bracke KR, Vermaelen KY and Pauwels RA. Matrix metalloproteinases in asthma and COPD. Curr Opin Pharmacol 2005; 5: 257-263.

7. Kheradmand F and Rishi K. The Role of Proteinases in Airway Remodeling. New York: Dekker, 2003, p. 749-765.

8. Parks WC and Shapiro SD. Matrix metalloproteinases in lung biology. Respir Res 2001; 2: 10-19.

9. Parks WC, Wilson $\mathrm{CL}$ and Lopez-Boado YS. Matrix metalloproteinases as modulators of inflammation and innate immunity. Nat Rev Immunol 2004; 4: 617-629.

10. Shapiro SD and Senior RM. Matrix metalloproteinases. Matrix degradation and more. Am J Respir Cell Mol Biol 1999; 20: $1100-1102$.

11. Turk BE and Cantley LC. Using peptide libraries to identify optimal cleavage motifs for proteolytic enzymes. Methods 2004; 32: 398-405.

12. Barnes PJ. Chronic obstructive pulmonary disease. N Engl J Med 2000; 343 (4): 269-280.

13. Shapiro SD. Elastolytic metalloproteinases produced by human mononuclear phagocytes: potential roles in destructive lung disease. Am. J. Respir. Crit. Care Med. 1994; 150: S160-S164. 
14. Shapiro SD. The macrophage in chronic obstructive pulmonary disease. Am J Respir Crit Care Med 1999; 160 (5 Pt 2): S29-S32.

15. Gomez DE, Alonso DF, Yoshiji $\mathrm{H}$ and Thorgeirsson UP. Tissue inhibitors of metalloproteinases: structure, regulation and biological functions. Eur. J. Cell Biol 1997; 74: 111-122.

16. Ohnishi K, Takagi M, Kurokawa Y, Satomi S and Konttinen YT. Matrix metalloproteinase-mediated extracellular matrix protein degradation in human pulmonary emphysema. Lab. Invest 1998; 78: 1077-1087.

17. Vignola AM, Riccobono L, Mirabella A, Profita M, Chanez P, Bellia V, et al. Sputum metalloproteinase-9/tissue inhibitor of metalloproteinase-1 ratio correlates with airflow obstruction in asthma and chronic bronchitis. Am. J. Respir. Crit. Care Med.1998; 158: 1945-1950.

18. Pauwels RA, Buist AS, Calverley PM, et al. GOLD Scientific Committee. Global strategy for the diagnosis, management, and prevention of chronic obstructive pulmonary disease: NHLBI/ WHO Global Initiative for Chronic Obstructive Lung Disease (GOLD) Workshop summary. Am J Respir Crit Care Med 2001; 163:1256-1276.

19. Johannessen A, Lehmann S, Omenaas ER, Eide GE, Bakke PS and Gulsvik A. Post-bronchodilator spirometry reference values in adults and implications for disease management. Am J Respir Crit Care Med 2006;173:1316-1325.

20. Rabe KF, Suzanne H, Antonio A, Barnes PJ, Buist SA, Calverley P, et al. Global Strategy for the Diagnosis, Management, and Prevention of Chronic Obstructive Pulmonary Disease GOLD Executive Summary. American Journal of Respiratory and Critical Care Medicine 2007; 176(6):532-555.

21. Waheed Z, Irfan M, Haque AS, Siddiqui NH, Awan S, Syed B, et al. Assessing two spirometric criteria of pre-bronchodilator and post-bronchodilator FEV1/FVC ratio in detecting air flow obstruction. JPMA 2001; 61(12): 1172-1175.

22. Johannessen A, Omenaas ER, Eide GE, Bakke PS and Gulsvik A. Feasible and simple exclusion criteria for pulmonary reference populations. Thorax 2007;62:792-798.

23. Kim DS, Kim YS, Jung KS, Chang JH, Lim CM, Lee JH, et al. Prevalence of chronic obstructive pulmonary disease in Korea: a population-based spirometry survey. Am J Respir Crit Care Med 2005; 172: 842-847.

24. Global Burden of Disease Study 2013, Collaborators (22 August 2015). "Global, regional, and national incidence, prevalence, and years lived with disability for 301 acute and chronic diseases and injuries in 188 countries, 1990-2013: a systematic analysis for the Global Burden of Disease Study 2013.". Lancet. 386 (9995): 743-800.

25. Vos T, Flaxman AD, Naghavi M, Lozano R, Michaud C, Ezzati M, et al. "Years lived with disability (YLDs) for 1160 sequelae of 289 diseases and injuries 1990-2010: a systematic analysis for the Global Burden of Disease Study 2010". Lancet 2012; 380 (9859): 2163-2196.

26. "Global, regional, and national age-sex specific all-cause and cause-specific mortality for 240 causes of death, 1990-2013: a systematic analysis for the Global Burden of Disease Study 2013." Lancet. 385: 117-171.

27. Mathers $C D$ and Loncar D. "Projections of Global Mortality and Burden of Disease from 2002 to 2030". PLoS Med 2006; 3 (11): e442.

28. Bjørn L. Global problems, local solutions: costs and benefits. Cambridge University Press 2013; p. 143.

\section{Authors Contribution:}

VR- Concept and design of the study, review of literature, analysis, acquisition of data, interpretation of data final approval of the manuscript; VKV- Study subject selection, concept and design of the study; RK- Selection of subjects for the study and intellectual contribution; RJ- Taken history and consent of the subjects and performed experimental research work; PS- Has been actively involved in preparing the first draft of the manuscript and done experimental research work; SP and AS- Drafting of the manuscript; MuR- contribution in the statistical analysis. 